\title{
LA ESTABILIZACIÓN MONETARIA EN CASTILLA BAJO CARLOS II
}

\author{
JOSÉ I. GARCÍA DE PASO * \\ Universidad Complutense de Madrid
}

\section{RESUMEN}

Durante gran parte del siglo xvir, Castilla sufrió el desorden monetario de la Casa de Austria, caracterizado por una inflación rampante, deflaciones puntuales y el monopolio del vellón en la circulación monetaria en detrimento de la plata. Por fin, un conjunto de medidas monetarias puestas en práctica en la década de 1680 bajo el reinado de Carlos II consiguió terminar con aquel desorden. En este trabajo modelizamos un sistema monetario bimetálico -plata y vellón- con el fin de analizar las causas del éxito de tales medidas.

\section{ABSTRACT}

During a large part of the XVIIth-century the Kingdom of Castile suffered the monetary reform of the Habsbourg Monarchy, characterized by sucessive periods of inflation and deflation, and an increase in the circulation of "vellon" in substitution of silver coins. Reforms introduced in 1680 by Carlos III ended the disorder of the previous phase. In this article we present a bimetallic model in orden to analyse the causes of the success obtained by the monetary reforms of Carlos III.

\section{INTRODUCCIÓN}

Una política monetaria caótica, dominada por las necesidades del erario público, fue el denominador común de la Castilla del siglo Xvi bajo distintos monarcas de la Casa de los Austrias. La emisión excesiva de moneda de vellón y la separación artificial entre su valor nominal legal y su valor intrínseco durante el reinado de Felipe III y en los primeros años del reinado de Felipe IV condujo a la erradicación gradual de la plata de la circulación monetaria, proceso que tuvo su inicio en la década de 1620. Ello generó un proceso inflacionista permanente y la creación de un premio de la plata

\footnotetext{
* Agradezco los comentarios y sugerencias de los tres evaluadores anónimos.
} 
sobre el vellón, que en diversas ocasiones trataron de ser atajados mediante bruscas medidas deflacionistas (por ejemplo, en 1628, 1642 y 1664). Sin embargo, estas medidas sólo tuvieron un éxito parcial y transitorio, ya que, aunque lograron reducir temporalmente el nivel de precios, no consiguieron la reintroducción de la plata en la circulación monetaria. Tras unas seis décadas de desórdenes monetarios, la conjunción de una serie de medidas de política monetaria puestas en práctica entre 1680 y 1686, durante el reinado de Carlos II, logró por fin estabilizar la economía desde el punto de vista monetario, consiguiendo reintroducir la plata en la circulación.

El objetivo de este trabajo es analizar qué diferenció esa política monetaria exitosa de la década de 1680 de las fracasadas medidas deflacionistas de décadas anteriores. Para ello, presentamos una versión heurística de un modelo monetario basado en una extensión al entorno bimetálico (plata y vellón) del modelo monometálico - plata - de Sargent y Velde (1999) y que se encuentra en García de Paso (1999a). El trabajo se estructura como sigue. En la sección II relatamos los antecedentes históricos a las medidas monetarias de la década de 1680 . Incluimos una serie de tablas que recogen la evolución en el siglo xvil del stock nominal de moneda de vellón en circulación, del premio de la plata y del índice de precios de los bienes (tanto cuando se expresan en moneda de vellón como cuando se expresan en moneda de plata). En la sección III hacemos una presentación heurística del modelo teórico que utilizamos en la sección IV para interpretar el surgimiento y la consolidación de la inflación del vellón en el siglo Xvir. En la sección $V$ repasamos las medidas monetarias de la década de 1680 y sus efectos, interpretando éstos a la luz del modelo teórico. Por último, en la sección VI resumimos el contenido del trabajo.

\section{LOS ANTECEDENTES HISTÓRICOS ${ }^{1}$}

Tras un largo y turbulento período de historia munetaria, los Reyes Católicos elaboraron una reforma del sistema monetario de la Corona de Castilla, promulgada mediante una Pragmática Sanción en Medina del Campo en 1497. Este sistema estaba basado en tres metales: oro, plata

${ }^{1}$ Estos antecedentes históricos están basados fundamentalmente en Hamilton (1975, 1983, 1988), Domínguez Ortiz (1960, 1967, 1973, 1984), Motomura (1994, 1997), Gelabert (1997), Pérez García (1990), Garzón Pareja (1980) y Velde y Weber (1997). Dadas las numerosas manipulaciones monetarias del período 1497-1679 y las lógicas limitaciones de espacio, hemos optado por hacer una presentación bastante esquemática de dichas manipulaciones, prescindiendo en buena medida del contexto político y presupuestario dentro 
y una aleación de plata y cobre, denominada vellón. La unidad de cuenta era el maravedí, que en la práctica no se correspondía con ninguna moneda metálica concreta, y había tomado el nombre de antiguas monedas, primero de oro, luego de plata y posteriormente de vellón, que habían circulado en siglos anteriores con el nombre preciso de maravedí (remontándose su origen a una moneda de oro existente en la Edad Media y que imitaba a los marabetinos de la dominación árabe). La moneda de oro establecida por los Reyes Católicos se denominó ducado o excelente, equivalente a 375 maravedís y con un grado de pureza del 98,958 por 100 . La moneda de plata se denominó real, equivalente a 34 maravedís y grado de pureza 93,055 por 100. La moneda de vellón se denominó blanca, equivalente a medio maravedí y grado de pureza 2,43 por 100 . En consecuencia, existian moneda de oro de denominación elevada, moneda de plata de mediana denominación y moneda de vellón de pequeña denominación.

La Pragmática de Medina del Campo en 1494 prohibió las cecas privadas en la Corona de Castilla y limitó a siete el número de cecas reales donde se podía acuñar la moneda. Se permitió la libre acuñación de oro y plata, si bien se limitó a diez millones de maravedís la cantidad de moneda de vellón en circulación.

En 1537, Carlos I modificó la moneda de oro, que ahora pasaba a denominarse escudo o corona, equivalente a 350 maravedís y grado de pureza del 91,666 por 100. En 1566, Felipe II incrementó hasta 400 maravedís el valor nominal de la corona, sin alterar su peso ni su pureza. En 1552 se redujo la pureza del vellón, al 1,909 por 100, mientras que en 1566 Felipe II la redujo nuevamente al 1,388 por 100 , al mismo tiempo que disminuyó su peso en un 14,583 por 100 . A partir de 1566 y hasta 1572 se acuñaron múltiplos de la blanca denominados cuartillos (8,5 maravedís), cuartos (4 maravedís) y ochavos ( 2 maravedís), todas ellas con una pureza del 21,5 por 100 (el llamado vellón rico). La ordenanza monetaria de 1566 estableció que no se pudiera acuñar moneda de vellón sin la licencia especial del rey Felipe II con el fin de evitar un exceso de circulación. Sin embargo, no existió limitación cuantitativa a dicha circulación.

A finales del reinado de Felipe II, el panorama monetario era el siguiente. Existían monedas de oro de 1 corona, 2 coronas o doblones y 4 coronas o dobles doblones, si bien de circulación escasa debido a su elevada denominación. Además, se acuñaban monedas de plata desde medio real hasta

del que se pusieron en práctica. Und explicación mucho más amplia de su incardinación dentro de dicho contexto puede encontrarse en García de Paso (1999b). 
8 reales, pasando por 1,2 y 4 reales, que eran las de mayor circulación. Asimismo, existían en circulación cuartillos, cuartos, ochavos y blancas, si bien solamente se acuñaban blancas, equivalentes a medio maravedí, con una pureza del 1,388 por 100 y un gramo de peso. El coste de la plata (14,5 miligramos) y el coste del cobre $(985,5$ miligramos) suponían alrededor del 60 por 100 del valor nominal (medio maravedí) de la blanca. Los costes de acunación representaban alrededor de otro 30 por 100, de manera que el señoreaje obtenido por las cecas reales se situaba alrededor del 10 por 100, de acuerdo con Motomura (1994).

El 31 de diciembre de 1596, el rey Felipe II emitió un decreto por el cual mandaba la acunación de cobre puro sin aleación de plata, si bien limitaba la acuñación hasta orden en contrario a 37,5 millones de maravedís anuales. El objetivo de Felipe II era aprovechar un nuevo sistema de acuñación de moneda (el sistema de «molinos») que se había instalado en la nueva ceca de Segovia (el «Nuevo Ingenio») para ahorrarse el coste de la plata en la acuñación de la moneda de vellón, por lo que el beneficio para la Corona de esa acuñación aumentaría, obteniendo mayores ingresos por señoreaje. En el citado decreto, Felipe II lo expresaba de esta forma:

«Las leyes de este reino disponen y ordenan la manera en que las casas de moneda labran las monedas de vellón y la proporción de plata que se añade en cada marco y todos los demás detalles necesarios para su ejecución. Pero hemos sido informados por gente de gran experiencia que la plata que se pone en esas monedas de vellón se pierde para siempre y no puede obtenerse beneficio de ella, excepto en su uso como dinero, y que la cantidad de plata que se pone en ese uso para las necesidades del comercio y el tráfico ordinarios en este reino es elevada. También hemos sido informados de que, como hemos puesto en marcha un nuevo ingenio en la ciudad de Segovia para acunar moneda, si pudiésemos acuñar toda la moneda de vellón allí, tendríamos la seguridad de que no podría ser falsificada, debido a que sólo podría imitarse una pequeña cantidad y no sin incurrir en un gran coste a menos que se disponga de un ingenio similar, del cual no existe ningún otro en este reino ni en los reinos vecinos. $Y$, por tanto, sería posible evitar el añadir plata a la moneda de vellón; habiendo considerado esto muy detenidamente y consultado, he permitido que en este Ingenio se labre todo el vellón que a partir de ahora se acuñe en este reino de Castilla sin añadir ninguna cantidad de plata y que se labren de esta manera cada año y hasta que no se ordene lo contrario 100.000 ducados $[37,5$ millones de mrs.] de monedas de vellón (es decir, 340.000 marcos anuales) del mismo valor y peso que los que corren actualmente en este reino; y que la mitad se labre en piezas de 4 maravedís, un tercio en piezas de 2 maravedís y un sexto en monedas de 1 maravedí; y, con el fin de evitar la inconveniencia resultante de un exceso de vellón en el reino, ordeno 
que se retire la misma cantidad de moneda que actualmente circula a medida que se acuña la nueva moneda hasta que toda la moneda vieja se consuma y toda la moneda de vellón de nuestro reino sea uniforme» ${ }^{2}$.

Según Domínguez Ortiz (1960), el valor nominal del stock de vellón antiguo en circulación rondaría los 1.300 millones de maravedís, por lo que al ritmo anual de 37,5 millones de maravedís se tardarian más de treinta años en sustituir la totalidad del vellón antiguo. Un mes después, el 1 de febrero de 1597, Felipe II revocó el decreto anterior de manera que la nueva moneda de vellón ya no sería de cobre puro, sino que incorporaría una pureza en plata del 0,3 por 100 . Asimismo, el 19 de julio del mismo año, el rey decretó el peso de las monedas de vellón a acuñar, siendo éste de 6,285 gramos para los cuartos, de 3,492 gramos para los ochavos y de 1,746 gramos para los maravedís. Por tanto, el resultado conjunto de estos tres decretos fue reducir la pureza de la moneda de vellón y reducir su peso - ya que la antigua blanca de medio maravedí pesaba un gramo, mientras que ahora la moneda de un maravedí pesaba menos de dos gramos-, pero limitando la acuñación anual a 37,5 millones de maravedís. Diez días después del último decreto, el 29 de julio de 1597, las Cortes de Castilla elevaron una protesta al rey indicando que las modificaciones introducidas en la moneda de vellón generarian inflación. Sin embargo, las acuñaciones se llevaron a cabo al ritmo anual de unos 37,5 millones de maravedís, por lo que entre 1597 y 1602 se acuñaron unos 190 millones de maravedís.

El 3 de junio de 1602, el rey Felipe III decretó la eliminación del 0,3 por 100 de plata en las nuevas acuñaciones de vellón ${ }^{3}$ y además que el peso de las nuevas monedas de cobre acuñadas se redujera a la mitad. Como entonces una moneda antigua circularía con el mismo valor facial pero un peso doble al de una moneda nueva, un año después, el 18 de septiembre de 1603, Felipe III emitió otro decreto obligando al resello de la moneda antigua, también denominada de calderilla. Así, el poseedor de una moneda antigua con valor nominal de $x$ maravedís la entregaría en la ceca y recibiría también $x$ maravedís en moneda nueva más una compensación por los costes ocasionados al acarrear la moneda hasta la ceca. El resto quedaría como ingreso de la corona en forma de señoreaje,

${ }^{2}$ Velde y Weber (1997), p. 3.

${ }^{3}$ Obsérvese que estas nuevas emisiones eran de cobre puro, por lo que no fueron de vellón propiamente dicho. Sin embargo, se siguió llamando moneda de vellón a esta moneda de cobre puro. Hasta 1660 no se volvió a acuñar una moneda con liga de cobre y plata y entonces ya se la denominó como moneda ligada. 
dispuesto para financiar ulteriores gastos públicos. El objetivo de recaudar señoreaje mediante esos expedientes se observa claramente en la siguiente comunicación del Consejo de Hacienda a Felipe III en mayo de 1601: «La [consignación] de que con mas promptitud se podrá preualer para estas necessidades tan precissas, seria el arbitrio de la moneda de vellon que estaua mandado por $V$. M. poner en execución...» ${ }^{4}$.

Tras una negociación entre las Cortes de Castilla y el monarca, el Decreto del 2 de noviembre de 1608 paralizó la acuñación de la nueva moneda de vellón con la contrapartida de una aprobación de ingresos presupuestarios adicionales. El compromiso de Felipe III fue el de paralizar la acuñación de vellón durante veinte años. Entre los Decretos de 1602 y 1608, se puso en circulación mediante nueva acuñación y resello un valor nominal de unos 1.100 millones de maravedís. Según Domínguez Ortiz (1960), entre 1599 y 1606 se habrían acuñado unos 2.300 millones de maravedís.

En 1617 las Cortes liberaron al rey Felipe III de la promesa de no emitir más monedas de vellón, si bien limitaron la acuñación a unos 300 millones de maravedís en 1617 y a unos 375 millones en 1618. Un año después, en 1619, las Cortes volvieron a prohibir la acuñación de vellón, pero ante la reapertura de las hostilidades con las Provincias Unidas, tras la finalización de la Tregua de los Doce Años, uno de los primeros decretos de Felipe IV (de 24 de junio de 1621) fue ordenar el labrado de 1.500 millones de maravedís, sin contar con la autorización de las Cortes, al que se fueron añadiendo ulteriores acuñaciones hasta que fueron suspendidas por la Real Cédula del 8 de mayo de 1626. En conjunto, en el período 1617-1626 se acuñaron 8.441 millones de $m r s$. y la acuñación total de moneda de vellón entre 1597 y 1626 alcanzó los 10.467 millones de $m$ rs.

A causa de la inflación galopante que se produce a partir de 1620 , y que tiene su punto álgido durante 1625 y 1626, en 1627 se promulgó una pragmática de tasas, la cual limitaba pormenorizadamente precios y salarios. También el 27 de marzo de ese mismo año se pusieron en marcha unas instituciones, denominadas Diputaciones para el consumo del vellón, cuyo fin era reducir en la medida de lo posible la cantidad de moneda de vellón en circulación. Estos organismos, con sede en Madrid y delegaciones en otras ciudades, comprarían vellón al valor nominal corriente, devolviendo a los propietarios anteriores el 20 por 100 del vellón entregado pero una vez perforado - de forma que su nuevo valor nominal pasaba

\footnotetext{
+ Gelabert (1997), p. 30.
} 
a ser cuatro veces menor al previo-. Además a los propietarios anteriores se les entregaba el 80 por 100 del vellón en deuda pagadera a los cuatro años en plata y que rendiría un 5 por 100 de interés anual. Los fondos para llevar a cabo estas operaciones se obtendrían parcialmente de los presupuestos públicos y parcialmente de actividades de préstamo y depósito, así como de otro tipo (como loterías). Esta operación de mercado abierto concebida como venta voluntaria del vellón por parte de sus tenedores fracasó, por lo que el 7 de agosto de 1628 se suprimieron las Diputaciones, se abolió la orden de tasas y se decretó la reducción a la mitad de su valor nominal de toda la moneda de cobre acuñada después de 1602 y de toda la moneda de vellón anterior a 1602 (calderilla) previamente resellada en 1603. El decreto contenía el compromiso del Rey de no acuñar más moneda de vellón en veinte años. Los efectos del decreto deflacionista fueron la reducción del nivel de precios (que se dejó sentir hasta 1636) y del premio de la plata.

En 1636, y ante la apertura formal de hostilidades con Francia del año anterior y las subsiguientes necesidades financieras, un Decreto de 11 de marzo ordenó el resello al triple de su valor previo de la moneda de calderilla que había sido resellada previamente en 1603. A partir de 1636 comienza una nueva escalada del nivel de precios y del premio de la plata, llegando a alcanzar este último el 200 por 100 en el segundo trimestre de 1642. El 29 de enero de 1638 se decretó un programa - con una duración de seis años- de fundido de la moneda de vellón acuñada después de 1602, a razón de 375 millones de maravedís anuales. La Corona obtendría el vellón —que posteriormente se fundiría - mediante una elevación de varios impuestos y mediante el pago que efectuarían los pueblos en proporción a su número de vecinos. Sin embargo, la moneda de vellón fundida fue mucho menor de la programada.

Las sucesivas derrotas sufridas en la guerra contra Francia, el inicio de la revuelta de Cataluña y la sublevación de Portugal significaron una carga presupuestaria ingente que el Gobierno no sabía cómo afrontar. Así, el 23 de diciembre de 1640, las Cortes de Castilla autorizaron un nuevo incremento del valor nominal del vellón, puesto en práctica en 1641 mediante los decretos de 11 de febrero y de 22 de octubre. El primero ordenó el resello al doble de las monedas de cuatro maravedís de cobre puro -excepto las labradas en la ceca de Segovia - y la entrega de la moneda de calderilla anteriormente resellada, trocándola por moneda de cobre puro. El segundo decreto ordenó el resello al triple de su valor nomi- 
nal de las monedas de dos y cuatro maravedís que habían sido acuñadas en la ceca de Segovia.

El decreto del 15 de septiembre de 1642 dispuso la reducción a dos maravedís del valor nominal de las monedas que corrían a doce y ocho maravedís; a un maravedí el de las monedas que corrían a seis y cuatro maravedís; y a medio maravedí - una blanca - el de las monedas en un maravedí. Esta reducción de los valores nominales de las monedas de cobre hizo que se aproximasen mucho el contenido metálico y el nuevo valor nominal. Así, el valor nominal de un marco de cobre acunado pasó a ser de 70 maravedís, mientras que el valor de ese mismo marco sin acuñar era de 68 maravedís. Escasamente dos meses después del decreto deflacionista, el 23 de diciembre de 1642, el Gobierno decretó una revalorización del real de plata del siguiente tenor. Se incrementó en un 25 por 100 el número de reales a acuñar a partir de un marco de plata, pasando desde 67 a 83,75 monedas. Al mismo tiempo, se elevó el valor nominal legal de los reales previamente acuñados en un 25 por 100 de tal forma que una moneda de 8 reales (con un valor nominal previo de 272 maravedís) pasaba a tener un valor nominal de 340 maravedís (esto es, pasaba a tener el valor nominal de 10 reales de los previamente acuñados). Esta medida de revaluación de la plata monetaria no se había tomado desde 1497 y sus efectos no pudieron dejarse sentir porque apenas tres meses después, el 12 de marzo de 1643, Felipe IV dio marcha atrás y volvió a dejar el real de plata en sus 34 maravedís iniciales y, al mismo tiempo, decretó la elevación del valor nominal de la moneda de calderilla al cuádruple, de manera que las monedas que corrían a un maravedí y a dos maravedís pasaban a tener, respectivamente, un valor nominal de cuatro y ocho maravedís. A partir de este conjunto de decretos del período que va desde septiembre de 1642 a marzo de 1643 , el nivel de precios disminuyó hasta 1646-1647, mientras que el premio de la plata cayó hasta el entorno del 25-30 por 100 en 1643 , para continuar un lento ascenso hasta alrededor del 50 por 100 hacia mediados del siglo.

A partir de 1646-1647 comienza un nuevo período de importantes alzas de precios que dura hasta 1653 , acompañado por una moderada pero permanente elevación del premio de la plata, situado alrededor del 50 por 100 . Durante 1650 y 1651 se deliberó acerca de retirar de la circulación toda la moneda de cobre puro, manteniendo solamente la de calderilla y la labrada en la ceca de Segovia entre 1597 y 1603. Sin embargo, ante las dificultades previstas en ese consumo del vellón y las perspectivas bélicas favorables a la recuperación de Cataluña, Felipe 
IV adoptó finalmente la decisión de revaluar nominalmente la moneda de cobre puro. Así las cosas, la pragmática de 11 de noviembre de 1651 ordenó el resello de toda la moneda de cobre hasta los valores nominales que había tenido antes del decreto del 15 de septiembre de 1642 (excepto de la calderilla, cuyo valor se había cuadruplicado ya en 1643). Al mismo tiempo, se ordenó la acuñación de 37,5 millones de maravedís en monedas de 2 maravedís.

El decreto de 25 de junio de 1652 deshizo la orden de resello de la pragmática de 1651, ordenó la desmonetización de la moneda de cobre puro a partir del 1 de enero de 1653 -mediante la promesa de indemnizar a sus poseedores con deuda pública garantizada por los impuestos sobre el tabaco- y redujo a un maravedí el valor nominal de las recién acuñadas monedas de 2 maravedís. La moneda de calderilla permanecería en los valores nominales de 4 y 8 maravedís que habían mantenido desde 1643 . Sin embargo, una pragmática de 14 de noviembre de 1652 ordenó la entrega de la calderilla para su desmonetización antes del 14 de junio de 1653 -con la misma promesa del decreto anterior-y revocó la orden anterior acerca de la moneda de cobre puro, por lo que ésta seguiría en circulación. El decreto de 21 de octubre de 1654 remonetizó la calderilla con sus mismos valores nominales anteriores (4 y 8 maravedís), pero sólo podría circular si sus poseedores la llevaban primero a resellar, devolviéndoseles solamente la mitad de lo entregado.

El período comprendido entre 1653 y 1657 está caracterizado por descensos de precios y por un mantenimiento del premio de la plata alrededor del 50 por 100 . La Real Cédula de 24 de septiembre de 1658 exigió la entrega de la moneda de cobre puro con el objetivo de fundirla y acuñar otra moneda, también de cobre puro, pero con un peso inferior (igual al de la moneda de calderilla); los poseedores recibirían el mismo valor nominal que entregaran pero en la nueva moneda más ligera. Sin embargo, el 26 de octubre del mismo año se decretó que, en vez de fundir las viejas monedas y acunar las nuevas, se llevaría a cabo un resello al doble de su valor nominal anterior. El decreto de 6 de mayo de 1659 suspendió el resello anterior de manera que las monedas de cobre puro volverían a tener el mismo valor nominal que antes de la cédula de 24 de septiembre del año anterior.

Como puede observarse en la Tabla 1, desde 1602 sólo se había acuñado moneda de cobre puro. Sin embargo, el decreto de 29 de octubre de 1660 ordenó labrar una nueva moneda ligada, con un contenido del 7 por 100 en plata, de la que se acuñarían 816 maravedís por marco y que resultó 
muy fácil de falsificar, por lo que un año después, el 29 de octubre de 1661 , se ordenó que fuese entregada a las cecas o empleada en el pago de contribuciones. Con posterioridad, se siguió labrando esta misma moneda ligada, pero ya no mediante el procedimiento de martillo, sino de molinos, más difícil de falsificar.

A partir de 1657 y hasta 1662 hay un período de alzas moderadas de precios y un incremento continuado del premio de la plata, hasta situarse alrededor del 80 por 100 a inicios del año 1662. A partir de 1662 se producen fuertes alzas de precios que duran hasta 1669 , junto con un espectacular incremento del premio de la plata — con la salvedad que comentamos a continuación-, el cual supera en 1669 el 180 por 100 . El decreto de 14 de octubre de 1664 paralizó la acuñación de la moneda ligada y redujo su valor nominal a la mitad, a la vez que prohibió la circulación de la moneda de cobre puro y la de calderilla. A consecuencia de este decreto, el premio de la plata baja desde el 150 por 100 en septiembre de 1664 hasta el 50 por 100 en el mes de octubre, para a partir de ahí comenzar de nuevo su escalada hasta superar el 180 por 100 en 1669. La primera parte de la década de los 70 está caracterizada por un suave descenso de precios y por un leve incremento del premio de la plata, que alcanza el 200 por 100 en 1675 . La segunda parte de la década se caracteriza por un nuevo repunte del nivel de precios y un lento pero progresivo incremento del premio de la plata, que llega a alcanzar el 275 por 100 en febrero de 1680 .

Es en este entorno histórico en el que se enmarcan las medidas de política monetaria que se ponen en práctica entre 1680 y 1686 . A continuación, presentamos datos de la evolución de la oferta nominal de vellón, del nivel general de precios y del premio de la plata.

\section{TABLA 1}

Emisiones de vellón y Stock nominal de vellón en circulación (en millones de mrs.)

\begin{tabular}{|c|c|c|c|c|c|c|c|c|}
\hline & \multicolumn{3}{|c|}{ Emisiones $(+o-)$} & & \multicolumn{4}{|c|}{ Stock nominal de vellón } \\
\hline & Calderilla & Cobre & Ligada & & Calderilla & Cobre & Ligada & Total \\
\hline $1596 \ldots \ldots \ldots \ldots . . . . . . . .$. & - & - & - & $1596 \ldots \ldots \ldots \ldots \ldots$ & 1.125 & 0 & - & 1.125 \\
\hline $1597-1599 a \ldots \ldots$ & 67 & - & - & $1597-1599 \ldots \ldots$. & 1.192 & 0 & - & 1.192 \\
\hline $1600-1602 a \ldots \ldots$ & 119 & - & - & $1600-1602 \ldots \ldots \ldots$ & 1.311 & 0 & - & 1.131 \\
\hline $1602-1604 r a \ldots .$. & 706 & 480 & - & $1602-1604 \ldots \ldots \ldots$ & 2.018 & 480 & - & 2.498 \\
\hline
\end{tabular}




\begin{tabular}{|c|c|c|c|c|c|c|c|c|}
\hline & \multicolumn{3}{|c|}{ Emisiones $(+o-)$} & & \multicolumn{4}{|c|}{ Stock nominal de vellón } \\
\hline & Calderilla & Cobre & Ligada & & Calderilla & Cobre & Ligada & Total \\
\hline $1604-1606 a \ldots . .$. & - & 480 & - & $1602-1606 \ldots \ldots$. & 2.018 & 961 & - & 2.979 \\
\hline $1607-1612 a \ldots \ldots$ & - & 174 & - & $1607-1612 \ldots \ldots$ & 2.018 & 1.135 & - & 3.153 \\
\hline $1612-1616 \ldots \ldots .$. & - & - & - & $1612.1616 \ldots \ldots \ldots$ & 2.018 & 1.135 & - & 3.153 \\
\hline $1617-1620 a \ldots \ldots$ & - & 1.673 & - & $1617-1620 \ldots \ldots$. & 2.018 & 2.807 & - & 4.825 \\
\hline $1621-1622 a \ldots \ldots$ & - & 614 & - & $1621-1622 \ldots \ldots$ & 2.018 & 3.421 & - & 5.439 \\
\hline $1623-1624 a \ldots \ldots$ & - & 3.590 & - & $1623-1624 \ldots \ldots$. & 2.018 & 7.011 & - & 9.029 \\
\hline $1625-1627 a \ldots \ldots$ & - & 2.564 & - & $1625 \cdot 1627 \ldots \ldots$. & 2.018 & 9.575 & - & 11.593 \\
\hline 1628-1635DV.. & $(1.009)$ & $(4.788)$ & - & $1628-1635 \ldots \ldots$ & 1.009 & 4.787 & - & 5.796 \\
\hline $1636-1637 r \ldots \ldots$ & 980 & - & - & $1636-1637 \ldots \ldots$. & 1.989 & 4.787 & - & 6.776 \\
\hline $1638-1640 a \ldots \ldots$ & - & 29 & - & $1638 \cdot 1640 \ldots \ldots$. & 1.989 & 4.816 & - & 6.805 \\
\hline $1641-1642 r \ldots \ldots$ & - & 5.337 & - & $1641-1642 \ldots \ldots \ldots$ & 1.989 & 10.153 & - & 12.142 \\
\hline $1642 D V \ldots \ldots \ldots \ldots$ & $(1.647)$ & $(7.745)$ & - & $1642 \ldots \ldots \ldots \ldots \ldots$ & 332 & 2.408 & - & 2.740 \\
\hline $1643-1650 R V .$. & 994 & - & - & $1643-1650 \ldots \ldots$ & 1.326 & 2.408 & - & 3.734 \\
\hline $1651 r \ldots \ldots \ldots \ldots . . . . . . . .$. & - & 7.224 & 一 & $1651 \ldots \ldots \ldots \ldots \ldots$ & 1.326 & 9.632 & - & 10.960 \\
\hline $1652-1657 D V .$. & - & $(7.224)$ & - & $1652-1657 \ldots \ldots$. & 1.326 & 2.408 & - & 3.734 \\
\hline $1658-1660 r \ldots \ldots$ & - & 319 & - & $1658 \ldots \ldots \ldots \ldots \ldots$ & 1.326 & 2.727 & - & 4.053 \\
\hline $1661 a \ldots \ldots \ldots \ldots . . . . . . .$. & - & - & 562 & $1661 \ldots \ldots \ldots \ldots \ldots$ & 1.326 & 2.727 & 562 & 4.615 \\
\hline $1662-1664 a \ldots \ldots$ & - & - & 562 & $1662-1664 \ldots \ldots$ & 1.326 & 2.727 & 1.125 & 5.178 \\
\hline $1665-1680 D V$. & - & - & $(562)$ & $1665-1680 \ldots \ldots$ & 1.326 & 2.727 & 562 & 4.615 \\
\hline
\end{tabular}

Fuentes de los incrementos y decrementos:

Para el stock inicial de calderilla, Motomura (1997).

Para las emisiones de calderilla y cobre anteriores a 1636, excepto para el resello de la calderilla en el período 1602-1604, Motomura (1997, Tabla 5). Para el resello de la calderilla en el período 1602-1604, Motomura (1997, Tabla 5A-5K). La cifra de lo resellado durante ese período que aparece en su Tabla 5 no concuerda con su desglose por distintas cecas (que aparece en las Tablas $5 \mathrm{~A}$ a $5 \mathrm{~K}$ ), por lo que hemos utilizado la suma de lo resellado en las distintas cecas.

Para el resello de la calderilla de 1636-1637, la suma de las Tablas 5A a 5K.

Para el resello de la moneda de cobre en 1641-1642, Pérez Garcia (1990, p. 165).

Para la devaluación de toda la moneda en 1642, cálculos propios.

Para la revaluación de la calderilla en 1643 , cálculos propios.

Para el resello de la moneda de cobre en 1651, cálculos propios.

Para la devaluación de la moneda de cobre en 1652, cálculos propios.

Para el resello de 1658, Domínguez Ortiz (1960, p. 273).

Para la acunaació de moneda ligada en el período 1661-1664, Domínguez Ortiz (1960, pp. 271-272).

Para la devaluación de la moneda ligada a partir de 1665 , cálculos propios.

Claves:

a: nueva acuñación.

$r$ : elevación del valor facial de la moneda mediante su resello.

ra: resello de la calderilla y nueva acuñación de moneda de cobre puro.

$D V$ : reducción del valor facial de la moneda (devaluación).

$R V$ : incremento del valor facial sin resello de la moneda (revaluación). 


\section{TABLA 2}

Premio de la plata

(cociente maravedí de vellón/maravedí de plata)

Antes de 1603: 1

1603: 1,01

1604-1615: 1,02

1616: 1,01

1617-1618: 1,02

1619: 1,03

\begin{tabular}{|c|c|c|c|c|c|c|}
\hline Año & Trimestre 1 & Trimestre 2 & Trimestre 3 & Trimestre 4 & $\begin{array}{c}\text { Promedio } \\
\text { anual }\end{array}$ & Premios \\
\hline 1620. & 1,0400 & 1,0458 & 1,0475 & 1,0383 & 1,0429 & 1,0400 \\
\hline $1621 \ldots$ & 1,0371 & 1,0523 & 1,0406 & 1,0450 & 1,0404 & 1,0400 \\
\hline $1622 \ldots$ & 1,0525 & 1,0561 & 1,0539 & 1,0632 & 1,0564 & 1,0588 \\
\hline $1623 \ldots$ & 1,0829 & 1,0893 & 1,0930 & 1,1506 & 1,1040 & 1,0833 \\
\hline $1624 \ldots$. & 1,1210 & 1,1191 & 1,1205 & 1,1298 & 1,1231 & 1,1143 \\
\hline $1625 \ldots$ & 1,1707 & 1,1670 & 1,2100 & 1,2701 & 1,2044 & 1,1120 \\
\hline $1626 \ldots$ & 1,3766 & 1,5000 & 1,5316 & 1,5241 & 1,4824 & 1,2943 \\
\hline $1627 \ldots$. & 1,5150 & 1,4096 & 1,3975 & 1,4133 & 1,4339 & 1,3768 \\
\hline $1628 \ldots$. & 1,4350 & 1,4627 & 1,4190 & 1,1345 & 1,3629 & 1,2943 \\
\hline $1629 \ldots \ldots$ & 1,1345 & 1,1345 & 1,2013 & 1,1978 & 1,1670 & 1,1669 \\
\hline $1630 \ldots \ldots$ & 1,1946 & 1,1938 & 1,2483 & 1,1903 & 1,2068 & 1,2140 \\
\hline $1631 \ldots \ldots \ldots \ldots$ & 1,1780 & 1,1983 & 1,1885 & 1,1818 & 1,1867 & 1,2025 \\
\hline $1632 \ldots \ldots \ldots \ldots$ & 1,1768 & 1,1831 & 1,1791 & 1,2010 & 1,1850 & 1,1767 \\
\hline $1633 \ldots \ldots \ldots \ldots \ldots$ & 1,2095 & 1,2330 & 1,2351 & 1,2502 & 1,2320 & 1,2079 \\
\hline $1634 \ldots \ldots \ldots \ldots$ & 1,2621 & 1,2798 & 1,2495 & 1,2604 & 1,2630 & 1,2575 \\
\hline $1635 \ldots \ldots \ldots \ldots \ldots$ & 1,2831 & 1,2619 & 1,2466 & 1,2779 & 1,2674 & 1,2496 \\
\hline $1636 \ldots \ldots \ldots \ldots$ & 1,2710 & 1,2470 & 1,2615 & 1,2756 & 1,2612 & 1,2491 \\
\hline $1637 \ldots \ldots \ldots \ldots . . . . .$. & 1,2910 & 1,2964 & 1,2907 & 1,2852 & 1,2913 & 1,2761 \\
\hline $1638 \ldots \ldots \ldots \ldots$ & 1,3243 & 1,3042 & 1,3500 & 1,3950 & 1,3434 & 1,3500 \\
\hline $1639 \ldots \ldots \ldots \ldots$ & 1,3438 & 1,2750 & 1,3717 & 1,4177 & 1,3520 & 1,2533 \\
\hline $1640 \ldots \ldots \ldots \ldots \ldots$ & 1,4391 & 1,4073 & 1,4583 & 1,4824 & 1,4468 & 1,4383 \\
\hline $1641 \ldots \ldots \ldots \ldots . . . . . .$. & 1,4370 & 1,4736 & 1,7316 & 1,9877 & 1,6575 & 1,4606 \\
\hline $1642 \ldots \ldots \ldots \ldots$ & 2,0204 & 2,8230 & 2,8685 & 1,2666 & 2,2445 & 1,7553 \\
\hline $1643 \ldots \ldots \ldots \ldots$ & 1,2516 & 1,2687 & 1,3167 & 1,2948 & 1,2830 & 1,2931 \\
\hline $1644 \ldots \ldots \ldots \ldots \ldots$ & 1,2938 & 1,2874 & 1,3139 & 1,3083 & 1,3009 & 1,3039 \\
\hline $1645 \ldots \ldots \ldots \ldots \ldots$ & 1,3047 & 1,2861 & 1,3983 & 1,3206 & 1,3274 & 1,3285 \\
\hline $1646 \ldots \ldots \ldots \ldots$ & 1,3771 & 1,4014 & 1,4163 & 1,3646 & 1,3876 & 1,4186 \\
\hline $1647 \ldots \ldots \ldots \ldots \ldots$ & 1,4027 & 1,3956 & 1,4025 & 1,3225 & 1,3808 & 1,3642 \\
\hline $1648 \ldots \ldots \ldots \ldots$ & 1,4023 & 1,4164 & 1,4181 & 1,4185 & 1,4138 & 1,4055 \\
\hline
\end{tabular}




\begin{tabular}{|c|c|c|c|c|c|c|}
\hline$A \bar{n} O$ & Trimestre 1 & Trimestre 2 & Trimestre 3 & Trimestre 4 & $\begin{array}{c}\text { Promedio } \\
\text { anual }\end{array}$ & Premios \\
\hline $1649 \ldots$ & 1,4376 & 1,4499 & 1,4633 & $1 ; 4563$ & 1,4518 & 1,4120 \\
\hline $1650 \ldots \ldots \ldots \ldots . . . . .$. & 1,4730 & 1,4933 & 1,5083 & 1,5527 & 1,5069 & 1,4663 \\
\hline $1651 \ldots \ldots \ldots \ldots$ & 1,5300 & 1,5300 & 1,5300 & 1,5300 & 1,5300 & 1,4838 \\
\hline $1652 \ldots \ldots \ldots \ldots$ & 1,5100 & 1,5000 & 1,5000 & 1,5000 & 1,5025 & 1,5000 \\
\hline $1653 \ldots$. & 1,5000 & 1,5000 & 1,5000 & 1,5000 & 1,5000 & 1,5000 \\
\hline $1654 \ldots \ldots$ & 1,5000 & 1,5000 & 1,5000 & 1,5200 & 1,5050 & 1,4538 \\
\hline $1655 \ldots \ldots \ldots \ldots . . . . . . .$. & 1,5000 & 1,5000 & 1,5000 & 1,5000 & 1,5000 & 1,5000 \\
\hline $1656 \ldots$ & 1,5000 & 1,5000 & 1,5000 & 1,5000 & 1,5000 & \\
\hline $1657 \ldots$ & 1,5625 & 1,5625 & 1,5625 & 1,5625 & 1,5625 & \\
\hline $1658 \ldots \ldots \ldots \ldots . . . . .$. & 1,6250 & 1,6250 & 1,6250 & 1,7083 & 1,6458 & \\
\hline $1659 \ldots \ldots \ldots \ldots . . . . . .$. & 1,7500 & 1,6250 & 1,5416 & 1,5000 & 1,6198 & \\
\hline $1660 \ldots \ldots \ldots$ & 1,5625 & 1,6250 & 1,5625 & 1,5625 & 1,5781 & \\
\hline $1661 \ldots \ldots \ldots \ldots \ldots$ & 1,5625 & 1,6458 & 1,6875 & 1,7291 & 1,6562 & \\
\hline $1662 \ldots \ldots \ldots \ldots$ & 1,8021 & 1,8125 & 1,8125 & 1,8125 & 1,8099 & \\
\hline $1663 \ldots \ldots \ldots \ldots$ & 1,8125 & 1,8958 & 2,0416 & 2,1250 & 1,9687 & \\
\hline $1664 \ldots \ldots \ldots \ldots . . . . .$. & 2,1250 & 2,2200 & 2,4683 & 1,5000 & 2,0783 & \\
\hline $1665 \ldots \ldots \ldots \ldots$ & 1,6300 & 2,0250 & 2,1658 & 2,1875 & 2,0020 & \\
\hline $1666 \ldots$ & 2,1875 & 2,2500 & 2,3556 & 2,3956 & 2,2967 & \\
\hline $1667 \ldots \ldots \ldots \ldots$ & 2,2500 & 2,4583 & 2,5000 & 2,5000 & 2,4270 & \\
\hline 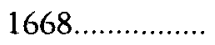 & 2,5000 & 2,5000 & 2,5000 & 2,6250 & 2,5312 & \\
\hline $1669 \ldots \ldots \ldots \ldots . . . .$. & 2,6250 & 2,6666 & 2,8750 & 2,7500 & 2,7291 & \\
\hline $1670 \ldots \ldots \ldots \ldots$ & 2,7500 & 2,7500 & 2,7500 & 2,7500 & 2,7500 & \\
\hline $1671 \ldots \ldots \ldots \ldots . . . .$. & 2,8125 & 2,8333 & 2,8750 & 2,8750 & 2,8489 & \\
\hline $1672 \ldots \ldots \ldots \ldots$ & 2,8750 & 2,8750 & 2,8750 & 2,8750 & 2,8750 & \\
\hline $1673 \ldots \ldots \ldots \ldots$ & 2,8750 & 2,8750 & 2,8750 & 2,8750 & 2,8750 & \\
\hline $1674 \ldots \ldots \ldots \ldots$ & 2,8750 & 2,8750 & 2,8750 & 2,9530 & 2,8945 & \\
\hline $1675 \ldots \ldots \ldots \ldots$ & 3,0000 & 3,0000 & 3,0000 & 3,0208 & 3,0052 & \\
\hline $1676 \ldots \ldots \ldots \ldots$ & 3,0625 & 3,0625 & 3,0833 & 3,1250 & 3,0885 & \\
\hline $1677 \ldots \ldots \ldots \ldots$ & 3,1250 & 3,1250 & 3,1250 & 3,1250 & 3,1250 & \\
\hline $1678 \ldots \ldots \ldots \ldots$ & 3,1875 & 3,1875 & 3,1875 & 3,1875 & 3,1875 & \\
\hline $1679 \ldots \ldots \ldots \ldots$ & 3,2500 & 3,2708 & 3,3541 & 3,3750 & 3,3125 & \\
\hline $1680 \ldots \ldots \ldots \ldots$ & 2,9166 & 1,5000 & 1,5000 & 1,5000 & 1,8541 & \\
\hline \multicolumn{7}{|c|}{$\begin{array}{l}\text { A partir de } 1681: 1,5000 \\
\text { A partir de noviembre de } 1686: 1,8825\end{array}$} \\
\hline
\end{tabular}

FuENTE: Para las cinco primeras columnas y el periodo previo a 1651, cálculos propios basados en Hamilton (1975), Tabla 7. Se trata de la media de los premios en Andalucía, Castilla la Vieja y Castilla la Nueva.

Para las cinco primeras columnas y el período posterior a 1651 , cálculos propios basados en Hamilton (1988), Cuadro 1. Se trata de la media de los premios en Castilla la Nueva.

Los premios son los contenidos en los documentos notariales de bienes post-mortem en Sevilla, según Aguado de los Reyes (1992). 
TABLA 3A

Indice de precios de los bienes

\begin{tabular}{|c|c|c|c|c|c|c|c|}
\hline & \multirow{2}{*}{$\frac{\text { Hamilton }}{(1)}$} & \multicolumn{2}{|c|}{ Martín-Aceña } & & \multirow{2}{*}{$\frac{\text { Hamilton }}{(1)}$} & \multicolumn{2}{|c|}{ Martín-Aceña } \\
\hline & & (2) & (3) & & & (2) & (3) \\
\hline $1600 .$. & 1,000 & 1,000 & 1,000 & & & & \\
\hline $1601 \ldots \ldots .$. & 1,061 & 0,860 & 0,860 & $1626 \ldots \ldots .$. & 0,871 & 1,232 & 0,827 \\
\hline $1602 \ldots \ldots \ldots$ & 1,009 & 0,827 & 0,827 & $1627 \ldots \ldots$. & 0,928 & 1,319 & 0,928 \\
\hline $1603 \ldots \ldots$. & 1,011 & 0,836 & 0,828 & 1628. & 0,946 & 1,392 & 1,013 \\
\hline $1604 \ldots \ldots$. & 1,023 & 0,916 & 0,898 & 1629. & 1,062 & 1,409 & 1,192 \\
\hline $1605 \ldots \ldots$. & 1,036 & 1,085 & 1,063 & 1630. & 0,997 & 1,406 & 1,166 \\
\hline $1606 \ldots \ldots . .$. & 1,002 & 1,331 & 1,305 & $1631 \ldots \ldots .$. & 0,985 & 1,530 & 1,291 \\
\hline $1607 \ldots \ldots . .$. & 0,973 & 1,330 & 1,304 & $1632 \ldots \ldots$ & 1,018 & 1,326 & 1,120 \\
\hline $1608 \ldots \ldots$. & 0,977 & 1,140 & 1,118 & $1633 \ldots \ldots$ & 0,968 & 1,251 & 1,008 \\
\hline $1609 \ldots \ldots$. & 0,930 & 1,032 & 1,012 & $1634 \ldots \ldots$ & 0,936 & 1,210 & 0,957 \\
\hline $1610 \ldots \ldots$. & 0,951 & 0,867 & 0,851 & $1635 \ldots \ldots$ & 0,924 & 1,195 & 0,935 \\
\hline $1611 \ldots \ldots$. & 0,916 & 0,860 & 0,843 & $1636 \ldots \ldots$. & 0,960 & 1,252 & 0,981 \\
\hline $1612 \ldots \ldots$. & 0,913 & 1,004 & 0,984 & $1637 \ldots \ldots$ & 0,998 & 1,323 & 1,028 \\
\hline $1613 \ldots \ldots \ldots$ & 0,922 & 0,969 & 0,950 & $1638 \ldots \ldots .$. & 0,974 & 1,377 & 1,045 \\
\hline $1614 \ldots \ldots . .$. & 0,956 & 0,863 & 0,846 & $1639 \ldots \ldots$. & 0,920 & 1,280 & 0,949 \\
\hline $1615 \ldots \ldots$ & 0,932 & 1,154 & 1,131 & $1640 \ldots \ldots$ & 0,885 & 1,146 & 0,781 \\
\hline $1616 \ldots \ldots$. & 0,975 & 1,236 & 1,223 & $1641 \ldots \ldots$ & 0,849 & 1,462 & 0,888 \\
\hline $1617 \ldots \ldots .$. & 0,984 & 1,285 & 1,260 & $1642 \ldots \ldots \ldots$ & 0,739 & 1,757 & 0,797 \\
\hline $1618 \ldots \ldots$ & 0,975 & 1,157 & 1,134 & $1643 \ldots \ldots$ & 1,024 & 1,295 & 1,026 \\
\hline $1619 \ldots \ldots$. & 0,931 & 1,061 & 1,030 & $1644 \ldots \ldots$ & 1,010 & 1,403 & 1,080 \\
\hline $1620 \ldots \ldots$. & 0,947 & 0,981 & 0,945 & $1645 \ldots \ldots$ & 0,969 & 1,475 & 1,090 \\
\hline $1621 \ldots \ldots$. & 0,941 & 1,025 & 0,977 & $1646 \ldots \ldots$. & 0,970 & 1,652 & 1,181 \\
\hline $1622 \ldots \ldots \ldots$ & 0,944 & 1,032 & 0,976 & $1647 \ldots \ldots$ & 0,984 & 1,583 & 1,176 \\
\hline $1623 \ldots \ldots$ & 0,925 & 1,251 & 1,136 & $1648 \ldots \ldots$. & 1,012 & 1,608 & 1,150 \\
\hline $1624 \ldots \ldots \ldots$ & 0,940 & 1,216 & 1,084 & $1649 \ldots \ldots$ & 1,019 & 1,623 & 1,130 \\
\hline $1625 \ldots \ldots$ & 0,905 & 1,176 & 0,954 & $1650 \ldots \ldots$ & 1,044 & 2,007 & 1,319 \\
\hline
\end{tabular}

(1) Indice de precios de los bienes expresados en plata. FuENTE: Cálculos propios basados en los datos no ponderados de Hamilton (1975), apéndice VIII. Se trata del promedio para tres regiones castellanas (Andalucía, Castilla la Vieja y Castilla la Nueva) y Valencia (base $1=1600$ ).

(2) Índice de precios de los bienes expresados en vellón. Fuente: Cálculos propios basados en los datos ponderados de Martín-Aceña (1992, Tabla 2) para Castilla la Nueva (base $1=1600$ ).

(3) Índice de precios de los bienes expresados en plata. FuENTE: Cálculos propios basados en datos de Martín-Acena (1992, Tabla 2), Hamilton (1975, Tabla 7) y Hamilton (1988, Cuadro 1) (base $1=1600$ ). 
TABLA 3B

Indice de precios de los bienes

\begin{tabular}{|c|c|c|c|c|c|}
\hline & \multicolumn{2}{|c|}{ Martín-Aceña } & & \multicolumn{2}{|c|}{ Martín-Aceña } \\
\hline & (1) & (2) & & (1) & (2) \\
\hline $1651 \ldots \ldots \ldots \ldots$ & 1,736 & 1,135 & $1676 \ldots \ldots \ldots \ldots$ & 2,365 & 0,766 \\
\hline $1652 \ldots \ldots \ldots \ldots$ & 1,765 & 1,175 & $1677 \ldots \ldots \ldots \ldots$ & 2,739 & 0,876 \\
\hline $1653 \ldots \ldots \ldots \ldots$ & 1,701 & 1,134 & $1678 \ldots \ldots \ldots \ldots$ & 3,017 & 0,947 \\
\hline $1654 \ldots \ldots \ldots \ldots$ & 1,716 & 1,140 & $1679 \ldots \ldots \ldots \ldots$ & 2,800 & 0,845 \\
\hline $1655 \ldots \ldots \ldots \ldots$ & 1,668 & 1,112 & $1680 \ldots \ldots \ldots \ldots$ & 2,496 & 1,346 \\
\hline $1656 \ldots \ldots \ldots \ldots$ & 1,732 & 1,155 & $1681 \ldots \ldots \ldots \ldots$ & 1,712 & 1,141 \\
\hline $1657 \ldots \ldots \ldots \ldots$ & 1,467 & 0,939 & $1682 \ldots \ldots \ldots \ldots$ & 1,371 & 0,914 \\
\hline $1658 \ldots \ldots$ & 1,601 & 0,973 & $1683 \ldots \ldots \ldots \ldots$ & 1,825 & 1,217 \\
\hline $1659 \ldots \ldots \ldots \ldots$ & 1,702 & 1,051 & $1684 \ldots \ldots \ldots \ldots$ & 1,898 & 1,265 \\
\hline $1660 \ldots \ldots \ldots \ldots$ & 1,825 & 1,156 & $1685 \ldots \ldots \ldots \ldots$ & 1,619 & 1,079 \\
\hline $1661 \ldots \ldots \ldots \ldots$ & 1,711 & 1,033 & $1686 \ldots \ldots \ldots \ldots$ & 1,414 & 0,904 \\
\hline $1662 \ldots \ldots \ldots \ldots$ & 1,665 & 0,920 & $1687 \ldots \ldots \ldots \ldots$ & 1,303 & 0,692 \\
\hline $1663 \ldots \ldots \ldots \ldots$ & 2,015 & 1,024 & $1688 \ldots \ldots \ldots \ldots$ & 1,350 & 0,717 \\
\hline $1664 \ldots \ldots \ldots \ldots$ & 2,677 & 1,288 & $1689 \ldots$ & 1,297 & 0,689 \\
\hline $1665 \ldots \ldots \ldots \ldots$ & 2,633 & 1,315 & $1690 \ldots \ldots \ldots \ldots$ & 1,316 & 0,699 \\
\hline $1666 \ldots \ldots \ldots \ldots$ & 2,554 & 1,112 & $1691 \ldots \ldots \ldots \ldots$ & 1,420 & 0,754 \\
\hline $1667 \ldots \ldots \ldots \ldots$ & 2,308 & 0,951 & $1692 \ldots \ldots \ldots \ldots$ & 1,548 & 0,822 \\
\hline $1668 \ldots \ldots \ldots \ldots$ & 2,736 & 1,081 & $1693 \ldots \ldots \ldots \ldots$ & 1,283 & 0,681 \\
\hline $1669 \ldots \ldots \ldots \ldots$ & 2,214 & 0,811 & $1694 \ldots \ldots \ldots \ldots$ & 1,452 & 0,771 \\
\hline $1670 \ldots \ldots \ldots \ldots$ & 2,008 & 0,730 & $1695 \ldots \ldots \ldots \ldots$ & 1,518 & 0,806 \\
\hline $1671 \ldots \ldots \ldots \ldots$ & 2,140 & 0,751 & $1696 \ldots \ldots \ldots \ldots$ & 1,479 & 0,786 \\
\hline $1672 \ldots \ldots \ldots \ldots$ & 2,189 & 0,761 & $1697 \ldots \ldots \ldots \ldots$ & 1,274 & 0,677 \\
\hline $1673 \ldots \ldots \ldots \ldots$ & 2,045 & 0,711 & $1698 \ldots \ldots \ldots \ldots$ & 1,648 & 0,875 \\
\hline $1674 \ldots \ldots \ldots \ldots$ & 2,123 & 0,733 & $1699 \ldots \ldots \ldots \ldots$ & 1,757 & 0,933 \\
\hline $1675 \ldots \ldots \ldots \ldots$ & 2,271 & 0,756 & $1700 \ldots \ldots \ldots$ & 1,498 & 0,796 \\
\hline
\end{tabular}

(1) Índice de precios de los bienes expresados en vellón. Fuente: Cálculos propios basados en los datos ponderados de Martín-Aceña (1992, Tabla 2) para Castilla la Nueva (base $1=1600$ ).

(2) Índice de precios de los bienes expresados en plata. Fuente: Cálculos propios basados en datos de Martín-Aceña (1992, Tabla 2), Hamilton (1975, Tabla 7) y Hamilton (1988, Cuadro 1) (base $1=1600$ ).

\section{UNA VERSIÓN HEURÍSTICA DEL MODELO UTILIZADO}

En esta sección se presenta una versión simplificada de un modelo monetario con el que vamos a explicar la razón del éxito de las medidas de la década de 1680 . Este modelo es una extensión a un entorno bimetálico 
del modelo de Sargent y Velde (1999) y puede encontrarse en García de Paso (1999a, secciones 3 y 4).

En la economía existen dos tipos distintos de monedas: el real de plata y la blanca de vellón ${ }^{5}$. En las transacciones grandes pueden utilizarse reales y blancas, pudiendo realizarse las transacciones pequeñas exclusivamente con blancas (por ejemplo, la moneda de plata pequeña a finales del siglo XVI era la de medio real, con un valor nominal equivalente al de 34 blancas y con el que aproximadamente se compraba un litro de leche; compras por cuantías inferiores había que realizarlas necesariamente con moneda de vellón) ${ }^{6}$.

La unidad de cuenta es el maravedí, por lo que los precios de los bienes de consumo $(P)$ se expresan en maravedís. Llamando $M_{\mathrm{b}}$ al número de blancas de vellón en circulación y $e_{\mathrm{b}}$ al valor nominal legal de la blanca de vellón fijado por la Corona, el producto $e_{\mathrm{b}} M_{\mathrm{b}}$ expresa el valor nominal de la moneda de vellón en circulación. Como las unidades de $e_{\mathrm{b}}$ son maravedís/blanca y $M_{\mathrm{b}}$ son blancas, entonces las unidades del producto $e_{\mathrm{b}} M_{\mathrm{b}}$ resultan ser maravedís. Del mismo modo, llamando $M_{\mathrm{r}}$ al número de reales de plata en circulación y $e_{\mathrm{r}}$ al valor nominal legal fijado por la Corona (número de maravedís/real), el producto $e_{\mathrm{r}} M_{\mathrm{r}}$ expresa el valor nominal de la moneda de plata en circulación. Por tanto, la suma $e_{\mathrm{r}} M_{\mathrm{r}}+e_{\mathrm{b}} M_{\mathrm{b}}$ indica la cantidad nominal de dinero (plata más vellón) en la circulación monetaria.

La Corona es propietaria monopolista de cecas donde el sector privado acude libremente a acuñar o a fundir moneda en las cantidades que desee. La Corona fija por ley el contenido metálico del real de plata (los gramos de plata contenidos en un real) y de la blanca de vellón (los gramos de cobre contenidos en una blanca). Al mismo tiempo, al ser las cecas propiedad de la Corona, ésta fija la tarifa que las cecas cargan al sector privado por cada moneda acuñada. En esa tarifa se incluyen tanto el coste de acunación, como el impuesto por señoreaje que desee percibir la Corona.

Este sistema monetario da origen a que el nivel de precios de los bienes esté acotado. Esto ocurre de la forma siguiente. Tanto el cobre como la plata tienen un precio mundial de mercado en términos de los demás bienes al cual pueden venderse o comprarse por el sector privado de nuestra

'Aunque en la sección II hemos visto que el sistema monetario castellano era trimetálico (oro, plata y vellón), el oro monetario en circulación ai inicio del siglo xvi era muy escaso. Por ello, los resultados obtenidos en un modelo bimetálico son prácticamente iguales que los que se obtienen en un modelo trimetálico (véase García de Paso, 1999a).

' Hamilton $(1975,1988)$ presenta estadísticas de precios para numerosísimos productos. 
economía. El sector privado decide cuándo llevar metal (plata o cobre) a acuñar a la ceca y también cuándo desea fundir monedas de plata o de cobre para obtener pasta de metal. Cuando la ceca acuña nuevas monedas, el sector privado incurre en dos costes: el coste del metal (lo que cueste en términos de los demás bienes en el mercado internacional) y la tarifa de acuñación. $\mathrm{Al}$ mismo tiempo, el sector privado obtiene un ingreso, que es el valor de mercado de las monedas acuñadas o la inversa del nivel de precios. Cuando el sector privado decide fundir monedas incurre en un coste (el valor de mercado de esas monedas) y, al mismo tiempo, obtiene un ingreso (el valor en el mercado internacional de la pasta de metal).

Así pues, el poder adquisitivo de las monedas de vellón y de plata no puede ser demasiado alto (en otras palabras, el nivel de precios no puede ser demasiado bajo), puesto que, en caso contrario, el ingreso obtenido por el sector privado de acunar esas monedas sería mayor que los costes en que incurre, de manera que su beneficio por moneda acuñada sería positivo. Entonces tendría un incentivo a acuñar una cantidad infinita de monedas para obtener beneficios infinitos. Del mismo modo, el poder adquisitivo de las monedas no puede ser demasiado bajo (es decir, el nivel de precios no puede ser demasiado alto), puesto que, en caso contrario, el ingreso obtenido por el sector privado de fundir esas monedas superaría al coste, de forma que su beneficio por moneda fundida sería positivo. En esa situación, el sector privado tendría un incentivo a fundir una cantidad infinita de monedas para obtener beneficios infinitos. Dada la imposibilidad de obtener beneficios infinitos de la acuñación o fundido de los metales (condición de ausencia de arbitraje), el nivel de precios se encontrará acotado (es decir, no será ni demasiado alto, ni demasiado bajo) en un intervalo que vendrá determinado por el punto de acuñación y el punto de fundido de cada moneda, tal y como se aprecia en el gráfico siguiente.

punto de acuñación

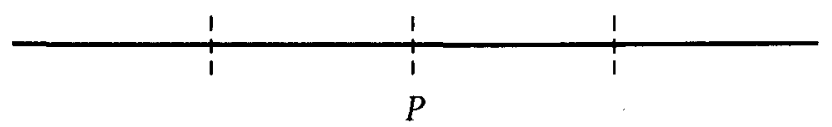

punto de acuñación

punto de fundido

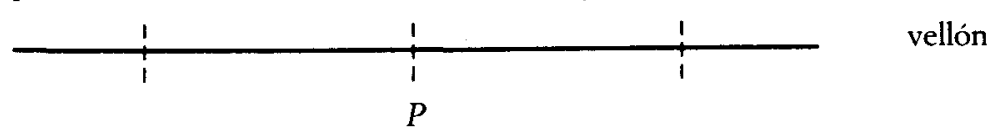


Supongamos, como en el esquema de arriba, que el punto de acuñación del real de plata está por encima del punto de acuñación de la blanca de vellón. En ese caso, si el nivel de precios $P$ cayese hasta llegar al punto de acuñación del real, entonces comenzarían a acuñarse reales de plata. Si todo el stock de plata no acuñado preexistente se termina acuñando y el nivel de precios sigue cayendo, entonces se llegaría hasta el punto de acuñación de vellón y comenzarían a acuñarse blancas de vellón. Del mismo modo, si el nivel de precios $P$ sube hasta llegar al punto de fundido del real, comenzarían a fundirse reales de plata y, una vez que se hubiesen fundido todos los reales preexistentes, entonces si el nivel de precios siguiera aumentando, comenzarían a fundirse blancas de vellón. Por lo tanto, si los puntos de acuñación no coinciden, sólo se acuña una de las monedas a un tiempo y solamente se fundiría una de las monedas a un tiempo si los puntos de fundido tampoco coinciden.

La distancia entre el punto de fundido y el punto de acuñación de cada moneda está directamente relacionada con la tarifa que cobra la ceca por acuñar esa moneda. Obsérvese que si el sector privado no incurriese en el coste de acuñación que le carga la ceca (la tarifa por acuñar, que incluye el impuesto de señoreaje), los puntos de acuñación y fundido coincidirían y el nivel de precios estaría fijo.

La tecnología de acuñación de la época conducía a que los costes de acuñación unitarios de las monedas de denominación baja (blancas de vellón) fuesen superiores a los de las monedas de denominación más elevada (reales de plata). Esto se debía a que el sistema de acuñación tradicional (o de martillo) implicaba que el procedimiento de hacer monedas pequeñas o grandes era esencialmente el mismo, con independencia del contenido o del tamaño de la moneda, de manera que el coste unitario variable de las distintas monedas era parecido. Sin embargo, dados unos costes fijos a repartir entre todos los tipos de monedas acunados, el coste fijo unitario de la moneda de plata —con mayor valor nominal- sería inferior al de la moneda de vellón. De forma que los costes unitarios globales decrecían con la denominación de la moneda acuñada. En consecuencia, habría de ocurrir que el intervalo de precios correspondiente a la moneda de plata fuese más estrecho que el de la moneda de vellón. Con los datos de Ulloa (1977) y Hamilton (1975), puede estirnarse el tamaño relativo a los intervalos de precios para ambas monedas. Entre 1497 y 1566 , el tamaño del intervalo de la blanca era unas 17 veces mayor que el del intervalo del real, y a partir de 1566 aquel tamaño fue unas 15 veces superior (véase el detalle en García de Paso, 1999b, capítulo 2). 


\section{LOS EFECTOS DE UN AUMENTO DE LA CIRCULACIÓN DE COBRE MONETARIO}

Supongamos que la economía recibe una dotación constante de bienes de consumo en cada período de tiempo $(D)$. En este caso, el nivel de precios de los bienes de consumo de la economía viene dado por la expresión ${ }^{7}$ :

$$
P=\frac{e_{\mathrm{r}} M_{\mathrm{r}}+e_{\mathrm{b}} M_{\mathrm{b}}}{D}
$$

Esta situación podemos asimilarla a la preexistente hacia finales del reinado de Felipe II. Pero a partir del decreto de Felipe II del 31 de diciembre de 1596, donde el Rey decreta que a partir de ese momento toda la moneda de vellón se acuñaría por cuenta de la Corona en la nueva ceca («Nuevo Ingenio») de Segovia, la Corona comienza a fijar de manera exógena el volumen de monedas de vellón en circulación. Por tanto, el sector privado deja de arbitrar con la acuñación y fundido de la moneda de vellón con el fin de obtener beneficios. Así pues, el intervalo de precios para los bienes de consumo correspondiente a la moneda de vellón desaparece. Sin embargo, el nivel de precios se mantendrá dentro del intervalo preexistente para la moneda de plata en la medida en que haya monedas de plata en circulación. Por una parte, si el nivel de precios cae lo suficiente, entonces se alcanzará el punto de acuñación de los reales de plata, por lo que ese metal comenzará a acuñarse y si el stock de plata no acuñado (y el flujo procedente por entonces de América) es importante, esto impedirá que el nivel de precios caiga aún más. Por la otra parte, si el nivel de precios sube lo suficiente, alcanzará el punto de fundido del real de plata, de manera que el stock de ese metal acuñado empezará a caer, si bien limitando ulteriores subidas del nivel de precios.

${ }^{7}$ Esta expresión indica implícitamente que el modelo utilizado incorpora una restricción de «efectivo por adelantado» o, dicho de otra forma, que se asume una velocidad de circulación del dinero con un valor constante e igual a la unidad. Uno de los evaluadores sugirió que se comprobase que la introducción de este supuesto sólo simplifica las relaciones dentro del modelo, sin efectar a los resultados básicos. Dicha extensión se lleva a cabo en García de Paso (1999b), donde se microfundamenta la función de demanda de dinero y se comprueba que los resultados que aquí se derivan sólo se modifican cuantitativamente pero no cualitativamente cuando permitimos que la velocidad de circulación no sea una constante. 
A partir de 1597, la Corona comienza en cada período su programa de emisiones y fundido de la moneda de vellón. A partir del decreto de 1602 , la cantidad de vellón acuñada en cada período supera a la cantidad fundida. $\mathrm{Al}$ mismo tiempo, el resello de 1603 provoca que el valor nominal de la moneda preexistente de vellón en circulación expresada en maravedís $\left(e_{\mathrm{b}}\right)$ se duplique pasando a ser $e_{\mathrm{b}}^{\prime}=2 e_{\mathrm{b}}$. Ambos fenómenos contribuyen a que se incremente el valor nominal de la moneda de vellón en circulación $\left[e_{\mathrm{b}} M_{\mathrm{b}}\right] \mathrm{y}$, por tanto, el valor nominal de la cantidad total - plata más vellón- de dinero en circulación $\left[e_{\mathrm{r}} M_{\mathrm{r}}+e_{\mathrm{b}}^{\prime} M_{\mathrm{b}}^{\prime}\right]$. Así, un aumento continuado de $e_{\mathrm{b}} M_{\mathrm{b}}$, como el que se produce a partir de 1602 , hará que el nivel de precios de los bienes de consumo aumente, si bien menos que proporcionalmente, pues

$$
P^{\prime}=\frac{e_{\mathrm{r}} M_{\mathrm{r}}+e_{\mathrm{b}}^{\prime} M_{\mathrm{b}}^{\prime}}{D}
$$

y $M_{\mathrm{r}}$ no crece al seguir situado el nivel de precios entre los puntos de acuñado y fundido de la plata. En consecuencia, inicialmente se produce una situación de crecimiento moderado de los precios, tanto menor cuanto menor sea el intervalo entre dichos puntos de acuñado y fundido para la plata. En esas fechas, el precio de mercado de un marco (unos 230 gramos de peso) de plata era de 65 reales y con él se acuñaban 67 reales, por lo que el señoreaje bruto (la longitud del intervalo para la plata) era de unos 2 reales, lo cual supone que el intervalo de fluctuación para el nivel de precios rondaba el 3 por 100 (puesto que $2 / 66 \cong 3$ por 100 ).

Sin embargo, sucesivos incrementos del stock nominal de la moneda de vellón $\left[e_{\mathrm{b}} M_{\mathrm{b}}\right.$, ya mediante la revalorización nominal -aumento de $e_{\mathrm{b}}$-, ya mediante la acunación directa —aumento de $M_{\mathrm{b}}$-, harán que el nivel de precios de los bienes de consumo alcance el punto de fundido de la moneda de plata. Llegados a ese punto, el sector privado comienza a obtener beneficios fundiendo los reales de plata.

Estos incrementos sucesivos de $e_{\mathrm{b}} M_{\mathrm{b}}$ contribuirán a que el stock de monedas de plata vaya siendo sustituido por la moneda de vellón. Durante el tiempo que dure la sustitución de la plata por el vellón, el nivel de precios permanecerá estancado en el punto de fundido de la moneda de plata, ya que la oferta nominal de dinero en circulación no aumenta (la oferta nominal de vellón en circulación aumenta en la misma cuantía en que disminuye la oferta nominal de plata en circulación). Pero si los incre- 
mentos del valor nominal del vellón en circulación son lo suficientemente elevados, entonces la tendencia al alza del nivel de precios continuaría y acabaría por fundirse toda la plata monetaria preexistente en circulación $\left(M_{\mathrm{r}}=0\right)$. A partir de ese momento, la oferta monetaria global pasará a ser de vellón.

En esta situación, ya sin monedas de plata en circulación, el nivel de precios vendrá determinado por la siguiente expresión:

$$
P=\frac{e_{\mathrm{b}} M_{\mathrm{b}}}{D}
$$

A partir de ese momento, incrementos ulteriores de $e_{\mathrm{b}} M_{\mathrm{b}}$ provocarán aumentos proporcionales de los precios de los bienes expresados en maravedís de vellón, esto es, una tasa de inflación similar a la tasa de crecimiento de la oferta nominal de maravedís de vellón. Dado que la plata ha dejado de formar parte de la oferta monetaria de la economía y ha desaparecido como moneda, pasando a ser tan sólo un bien de consumo cualquiera, comenzará a cotizarse en el mercado como ese bien de consumo que es. Por tanto, tendrá un precio relativo en el mercado internacional en términos de los bienes de consumo, determinado por su contenido metálico, y a ese precio relativo tendrá que ajustarse su cotización interna. De modo que surgirá un «premio» de la plata sobre el vellón, determinado por el cociente entre el precio del mercado internacional del contenido metálico de un real de plata y el precio legal (valor facial) de ese mismo real de plata en la economía castellana. Cuanto mayor sea el nivel de precios de los bienes de consumo expresados en maravedís de vellón, mayor poder adquisitivo interno tendrá el contenido metálico de un real de plata, por lo que el premio de la plata será mayor. Dado que el nivel de precios de los bienes de consumo aumenta cuanto mayor sea el valor nominal de la moneda de vellón $\left(e_{\mathrm{b}}\right)$ y cuanto mayor sea el volumen de moneda de vellón en circulación $\left(M_{\mathrm{b}}\right)$, entonces el premio de la plata será tanto más alto cuanto mayores sean el volumen de blancas de vellón en circulación y el valor nominal legal de la blanca. Al mismo tiempo, cuanto mayor sea el contenido metálico del real de plata (cuanto mayor sea su peso), mayor será su poder adquisitivo $\mathrm{y}$, por tanto, mayor será el premio de la plata. Por otra parte, cuanto mayor sea el valor nominal de la moneda de plata $\left(e_{\mathrm{r}}\right)$, menor diferencia habrá entre el poder adquisitivo interno 
de su contenido metálico y el poder adquisitivo interno de su valor nominal. Por tanto, el premio de la plata sobre el vellón es menor. Así pues, el proceso de expansión de la circulación del vellón monetario iniciado a finales del reinado de Felipe II y al inicio del de Felipe III terminó conduciendo a una inflación y a un premio de la plata sobre el vellón que se manifestaron con fuerza a partir de la década de 1620. Dado que la oferta monetaria (plata más vellón) rondaba los 9.000 millones de maravedís al final del siglo xvi, en la Tabla 1 puede observarse cómo hasta 1623-1624 la oferta nominal de vellón estuvo sustituyendo a la oferta nominal de plata en circulación, por lo que el crecimiento de precios no se notó en la práctica, ni en términos de vellón ni en términos de plata (véase la Tabla 3). Pero hacia 1624, y una vez sustituida la oferta nominal previa de plata mediante vellón, se desató el proceso de inflación que condujo a Felipe IV y al Conde-Duque de Olivares a fijar techos administrativos a los precios (1627), a intentar la retirada de vellón de la circulación mediante operaciones de mercado abierto (1627-1628) y finalmente a la deflación de 1628 mediante la reducción a la mitad del valor nominal del vellón en circulación ${ }^{8}$.

\section{EL ANÁLISIS DE LAS MEDIDAS DE POLÍTICA MONETARIA DE LA DÉCADA DE 1680}

En el medio siglo posterior a la deflación de 1628, las urgentes necesidades de la Hacienda de la Casa de Austria volvieron a precisar en numerosas ocasiones de la obtención de señoreaje vía la manipulación de la moneda, tal y como se relata en la sección II. Ello condujo a la larga a un incremento secular de precios y a que el premio de la plata llegase a situarse en el 275 por 100 en el mes de febrero de 1680. Ante esta situación, el Gobierno de Carlos II se decidió a aplicar de nuevo una medida deflacionista, de corte similar a las aplicadas anteriormente en 1628,

* Véase en García de Paso (1999a) cómo, ya en 1609, el Padre Juan de Mariana había previsto acertadamente lo que habría de ocurrir casi veinte años después en el bienio 1627-1628 en su Tratado y Discurso sobre la Moneda de Vellón. Por criticar en esa obra la política inflacionista de Felipe III y de su valido el Duque de Lerma, el Padre Mariana tuvo graves problemas con la Inquisición. Irónicamente, en su opúsculo Tira la Pieára y Esconde la Mano o El Chitón de las Tarabillas, escrito en 1629, Francisco de Quevedo utiliza los argumentos antiinflacionistas contenidos en el Tratado del Padre Mariana para defender el decreto deflacionista de agosto de 1628 a mayor gloria de su entonces protector, el Conde-Duque de Olivares, valido de Felipe IV. 


\section{2, 1652 y 1664 y con el objetivo de reintroducir la plata en la circulación} monetaria.

Esa medida, el decreto de 10 de febrero de 1680 , redujo de nuevo a la mitad el valor nominal de la moneda ligada. $\mathrm{Al}$ mismo tiempo, legalizó la moneda falsa de vellón permitiendo su circulación a una cuarta parte de su valor facial - la nacional - y a una octava parte - la procedente del extranjero- ${ }^{9}$. Un nuevo decreto del 14 de marzo ordenó la acuñación

${ }^{y}$ Henry Kamen (1981, p. 170) escribe: «La reforma [de 1680] formaba parte de un programa inteligente de fomento planeado por [el valido y hermanastro de Carlos II, muerto en el verano de 1679] Juan José de Austria. En 1679, sus ministros empezaron a estudiar las formas de dar al país una moneda estable. Las largas discusiones desembocaron en la decisión de devaluar, tomada por la Junta de Moneda el 13 de agosto de 1679, cuando don Juan se encontraba enfermo en cama. El decreto final, promulgado dos semanas antes de que el duque de Medinaceli llegara al poder como primer ministro, fue, por tanto, el indudable testamento de don Juan.» En la nota al pie 229 de esa misma página, Kamen indica que «debo la identificación fundamentada del decreto de 1680 a don Juan a la tesis doctoral de Mario L. Sánchez, «Attempts at Reform», Notre Dame, 1976, p. 128.

La pragmática sobre reforma de la moneda de 10 de febrero de 1680 tiene el siguiente tenor (Garzón Pareja, 1980, apéndice 4): «Don Carlos, por la gracia de Dios... Sabed, que el Rey D. Felipe Quarto, mi señor y Padre... deseando moderar el premio excesivo de las monedas de oro y plata... en Pragmática de 29 de octubre de 1660, mandó subrogar otra moneda con liga de plata... Pero saliendo muy contrarios los efectos y desordenándose los precios del comercio mayor y menor de estos Reynos, pareció conveniente reducir esta moneda ligada de molino a la mitad de su valor, como se executó por pragmática de 14 de diziembre de 1664. Y aunque por este medio, baxando cada marco a su natural estimación se hizo más tratable el comercio, y consiguió que se moderasen los mantenimientos, los males y daños de estos Reynos con la moneda falsa y de puro cobre, que ban introducido en ellos los enemigos de la Corona, se ban recrecido tan sobresalientes y graves perjuyzios, que piden pronto y eficaz remedio.. Visto por los del nuestro Consejo y con nos consultado, fue acordado que deviamos mandar dar esta nuestra carta, que queremos tenga fuerza de ley y Pragmática sanción, como si fuera fecha y promulgada en Cortes. Por la qual queremos y mandamos, que sin embargo de lo dispuesto por la referida Pragmática de 14 de octubre de 1664, en que la dicha moneda de molinos ligada de plata, labrada en las Casas de Monedas destos Reynos, se mandó baxar y quedó reduzido el marco della a doze reales, y las pieças de diez $y$ seis maravedís a ocho, y las de ocho a quatro, $y$ las de quatro a dos, y las de dos a uno, desde abora se baxe y quede reduzida y corra el marco de moneda ligada legitima solo a la quarta parte, que son tres reales, y a este respecto las pieças de ocho maravedis que valgan dos maravedis; las de quatro maravedis un maravedi y las demás de dos maravedís y un maravedí a esta proporción. Y que toda la moneda de puro cobre que se ba fabricado en estos Reynos a imitación de la legitima, cuyo peso con poca diferencia corresponde una a otra en las pieças que deve tener cada marco, aunque no en la liga, ni en la perfección de la forma, efigie y armas en que se distingue y dexa reconocer, también quede reduzida a la quarta parte del valor con que boy corre, de manera que la pieça de ocho maravedís quede en dos maravedis, siguiendo en todo la misma forma y regla que queda expresada en el capitulo antecedente, sin permitir haya diferencia en quanto a su valor en manera alguna, atendiendo a la mayor libertad de los contratos y facilitar el uso y comercio della. Que toda la demás moneda de molino, fabricada fuera destos Reynos e introduzida en ellos por extrangeros y naturales, que no solo no tiene la ley, liga y peso que la legitimamente fabricada en las Casas de Moneda, ni el peso que la falsa fabricada dentro del Reyno; pero es tan delgada y feble, que ni en el 
de 750 millones de mrs. en una nueva moneda de cobre puro, con un valor nominal de dos maravedís y con un contenido metálico similar a su valor nominal. Esta moneda se acuñó hasta 1695. Como se vio que esta importante deflación era insuficiente para hacer que saliera moneda de plata a la circulación, mediante el decreto de 22 de mayo de 1680 se prohibió la circulación de la moneda ligada ${ }^{10}$.

El resultado de la desmonetización de la moneda ligada y de la emisión de moneda de cobre con valor intrínseco similar al valor nominal fue una deflación generalizada en la Corona de Castilla, cayendo los precios en el período 1680-1682 un 51 por 100. El premio de la plata bajó inme-

peso ni en la forma corresponde, antes fatalmente se diferencia y manifiesta a la vista, quede reduzida a la octava parte del valor que oy corre...».

${ }^{10}$ El tenor de esta nueva pragmática es el siguiente (Garzón Pareja, 1980, apéndice 5): «... mandamos publicar una nuestra Ley y Pragmática en 10 de febrero de este año, reduziendo y baxando esta moneda de molinos, asi la ligada con plata como la que es falsa y de puro cobre labrada dentro destos Reynos y fuera dellos, a la quarta parte de los ocho y quatro maravedís a que corria antes de la publicación; considerando que con esta baxa y quedando en solo la quarta parte, se acudía al reparo de todos los daños y perjuizios que se tenian presentes y tan experimentados en la alteración del comercio y precios de los mantenimientos, y que las cosas volverian a su antiguo ser. Tanto más baviendo resuelto por otra mi Cedula de 14 de março de este año, que toda esta moneda de vellón de molinos se fuera consumiendo por quenta de mi Real Hazienda, y que de las pastas que procediese de la solo cobre, se fuesen labrando y subrogando otra en moneda gruesa de vellón, al mismo peso y valor de los dos maravedís a que oy corre en estos Reynos la del vellón grueso, para que por medio deste consumo de la de molinos, no quedase ni el nombre de ella, como con efecto se ba ido y está ejecutando. $Y$ quando desta resolución ( $y$ que la costa y gastos deste consumo, se mandó corriese por quenta de mi Real Hazienda, y no de los particulares que la tienen) se esperaba que las cosas del comercio y precio general de los bastimentos y demás géneros para la vida bumana se reduzieran a justicia y equidad, se ban experimentado y están experimentando al presente los mismos daños $e$ inconvenientes que se padecian antes de la baxa desta moneda, porque como todavia corre en el comercio con el valor de dos maravedís a que ba quedado reduzida, aunque con tanto descrédito y desestimación por su baja calidad, y por no baverse podido en tan corto tiempo como ba pasado después de la baxa, acabar de hazer el consumo ni la nueva labor que de su pasta se está baziendo en moneda gruesa, y que de mantenerse en el comercio no se pueden atajar las continuas entradas de moneda falsa que se bazen por los extrangeros, por la gran ganancia que todavia les ba quedado por ser tan feble, y que cada dia son mayores los perjuizios que por esta razón reciben mis súbditos y vasallos y el comercio universal de mis Reynos, y que en conciencia y justicia somos obligados de dar al Reyno moneda legitima y de valor intrínseco y legal, para que con estos gozen mis Reynos, súbditos y vasallos de todas las otras comodidades y utilidades que de la igualdad de la moneda y de la reducción a su justo valor, necesaria y precisamente ban de resultar siguiendo los exemplos de otros Reynos y provincias, y lo executado en estos antes que se biziese esta labor de molinos, y que el remedio único de todos estos daños es el probibir el uso de esta moneda... Y por quanto por Pragmáticas de 7 de setiembre de 1641, y 11 de noviembre de 1651 está mandado que el premio de la plata no exieda de cinquenta por ciento, y a este respecto el oro... Queremos y mandamos que abora se guarden y cumplan en todo lo que a este fuere anexo y concerniente y que por ellas estuviere dispuesto, y contra su tenor no se pueda ir en manera alguna." 
diatamente desde el 275 por 100 en febrero de 1680 hasta el 50 por 100 en el mes de marzo, valor en el que se mantuvo constante hasta final del siglo. Algunos autores han apuntado que la reforma monetaria de 1680 acabó con el desorden monetario en Castilla. Así, por ejemplo, Pierre Vilar (1969) argumenta que el paquete de medidas contenido en los decretos de 1680 fue una auténtica operación quirúrgica que, por vez primera en el siglo, se vio coronada por el éxito. Velde y Weber (1997) señalan que «esta acuñación marcó el fin de la inflación del vellón en Castilla» y esto es rigurosamente cierto, puesto que el nivel promedio de precios en vellón del período $1680-1700$ fue alrededor de un 46,5 por 100 inferior al nivel de precios en vellón de 1679 . Sin embargo, no puede considerarse que las medidas adoptadas en 1680 fueran totalmente exitosas, tal y como claramente pone de mnifiesto Domínguez Ortiz (1967), dado que la deflación provocada fue insuficiente para hacer reaparecer la circulacion de la moneda de plata (que era otro de los objetivos de la reforma monetaria), por lo que el 9 de octubre de 1684 se volvió a remonetizar la moneda ligada adjudicándole un valor nominal igual al que había tenido entre 1664 y 1680 .

Debido a que las medidas deflacionistas de 1680 no habían logrado la reintroducción de la moneda de plata en la circulación monetaria, finalmente, el conde de Oropesa, nuevo primer ministro de Carlos II, tomó la determinación de adoptar un paquete de medidas monetarias de corte inflacionista y relativas a la plata, similares a las que había puesto en práctica Felipe IV entre diciembre de 1642 y marzo de 1643. El decreto de 14 de octubre de 1686, por una parte, redujo el peso de los nuevos reales a acuñar en un 25 por 100 . De un marco de plata del que se acuñaban 67 reales, a partir del decreto se acuñarían 84 . Por otra parte, incrementó en un 25 por 100 el valor nominal de las monedas de plata previas a la disposición. Así, las antiguas monedas de 8 reales - con un valor nominal de 272 mrs. - pasarían a llamarse escudos de plata y se valorarían en 10 reales de los nuevos - con un valor nominal de $340 \mathrm{mrs}$. - Además, se estableció una tarifa de acuñación para la moneda de plata de 2,75 reales por marco ( 2 de costas de acuñación y 0,75 de señoreaje) y posteriormente se eliminó el señoreaje, con lo que la tarifa de acuñación se redujo hasta el 2,4 por 100 del nuevo valor nominal del marco de plata acuñado.

Así pues, este decreto sí marcó el fin del desorden monetario en la Castilla del siglo xvu. Según Domínguez Ortiz (1969): «... La plata abandonó sus escondrijos y comenzó a salir al mercado. Los precios dejanon de caer $e$ iniciaron una modesta recuperación...». Tras un repunte transitorio en 
1683-1684, los precios expresados en vellón continuaron cayendo durante 1685 y 1686 para iniciar una recuperación suave a partir de 1687, aumentando un promedio del 1 por 100 anual hasta el final del siglo.

¿Por qué las medidas inflacionistas referidas a la moneda de plata que tomó el Conde de Oropesa en 1686 tuvieron el éxito que se había negado a anteriores planes de estabilización monetaria? La respuesta está en que sus efectos se dejaron sentir sobre una economía que previamente había soportado un plan de estabilización deflacionista concerniente a la moneda de vellón.

En el modelo que hemos esbozado en la sección III, la reintroducción de la plata en la circulación monetaria puede lograrse de dos formas: i) mediante una deflación que provoque que el nivel de precios de los bienes de consumo $P$ caiga hasta el punto de acuñación del real de plata. Para ello debe reducirse el valor nominal de la moneda de vellón en circulación $\left(e_{\mathrm{b}} M_{\mathrm{b}}\right)$. Esta reducción del valor nominal del vellón en circulación puede, a su vez, lograrse de dos maneras distintas; por la retirada de la circulación de moneda de vellón (una caída de $M_{\mathrm{b}} \mathrm{y}$, por ende, de $e_{\mathrm{b}} M_{\mathrm{b}}$ ), vía una operación de mercado abierto contractiva o una prohibición efectiva de su circulación, o por la reducción del valor nominal legal de la moneda de vellón en circulación (un descenso de $e_{\mathrm{b}} \mathrm{y}$, por tanto, de $e_{\mathrm{b}} M_{\mathrm{b}}$; ii) mediante medidas que hagan que el punto de acuñación de la plata aumente hasta el nivel corriente de precios. A su vez, la elevación del punto de acuñación de la plata puede lograrse de tres maneras diferentes: por una revalorización nominal del real de plata (un incremento de $e_{\mathrm{r}}$ ), por una reducción del contenido metálico del real de plata, o por una reducción o eliminación de la tarifa de acuñación de la moneda de plata que acerque su punto de acuñación a su punto de fundido.

Los decretos de febrero y de mayo de 1680 generaron una devaluación nominal de la moneda de vellón (una disminución de $e_{\mathrm{b}}$ ) y una desmonetización de una parte del volumen de moneda de vellón en circulación - la moneda ligada - (una caída de $M_{\mathrm{b}}$ ), lo que implicó una caída de la oferta nominal de vellón en circulación y un descenso del nivel de precios de los bienes de consumo y del premio de la plata sobre el vellón. Sin enibargo, la devaluación fue insuficiente para lograr la acuñación de moneda de plata. En este sentido, el nivel de precios

$$
P=\frac{e_{\mathrm{b}} M_{\mathrm{b}}}{D}
$$


cayó, pero de manera insuficiente como para llegar hasta el punto de acuñación del real de plata (véase el esquema siguiente).

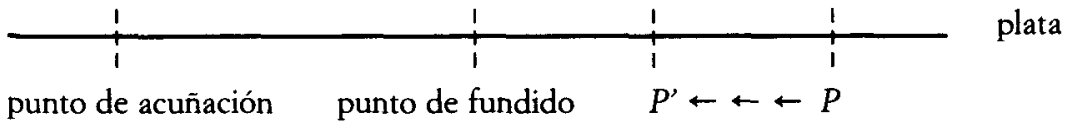

El decreto de 9 de octubre de 1684 deshizo parcialmente los efectos de las medidas de 1680 al remonetizar de nuevo la moneda ligada.

Mediante el decreto de 14 de octubre de 1686, el Conde de Oropesa redujo el contenido metálico en plata del real, revalorizó nominalmente la moneda de plata (un incremento de $e_{\mathrm{r}}$ ) y redujo la tarifa de la acuñación de moneda de plata. Estas tres medidas fueron en la misma dirección de elevar el punto de acuñación de la plata hasta igualarse con el nivel corriente de precios (véase el esquema de abajo).

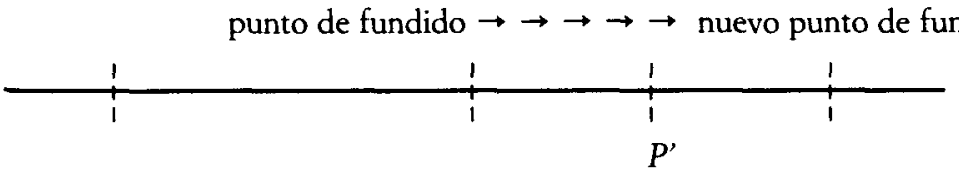

punto de acuñación $\rightarrow \rightarrow \rightarrow \rightarrow \rightarrow$ nuevo punto de acuñación

Esta combinación de medidas contenidas en el decreto de 1686 logró elevar el punto de acuñación de la plata hasta el nivel de precios preexistente, lográndose la reintroducción de la plata en la circulación monetaria. Al mismo tiempo, dado que la oferta monetaria nominal de vellón permaneció inalterada y la oferta nominal de plata en circulación pasó a ser positiva, la oferta monetaria global se incrementó, lo que implicó una suave elevación de los precios, que aumentaron alrededor de un 1 por 100 anual desde 1687 hasta final del siglo.

La conjunción de los paquetes de medidas de 1680 y de 1686 tuvo éxito a la hora de reintroducir la plata en la circulación monetaria, un éxito esquivo a la polítiva monetaria de la Casa de Austria durante las seis décadas anteriores. El motivo fue que -aunque el primer paquete era de corte deflacionista y el segundo, de corte inflacionista- los dos fueron consistentes entre sí, al ir ambos en la línea de acercar el nivel corriente de precios y el punto de acuñación de la plata. 


\section{CONCLUSIONES}

En este trabajo se han presentado los hitos históricos más relevantes de lo que se ha dado en llamar «el caos monetario» de la Castilla del siglo xvi. Dicho «caos» terminó merced a una política monetaria acertada instrumentada durante la década de 1680, bajo el reinado de Carlos II. Esa exitosa política monetaria incluyó un paquete de medidas de corte deflacionista puesto en marcha en 1680 , junto con otro paquete de medidas de distinto carácter y corte inflacionista, instrumentado en 1686. Al mismo tiempo, hemos mostrado cómo un sencillo modelo monetario basado en una extensión del modelo de Sargent y Velde (1999) a un entorno bimetálico plata-vellón es capaz de explicar cómo ese conjunto de medidas diversas - y, en cierto modo, de carácter opuesto- fue capaz de terminar con un desorden monetario casi secular.

\section{BIBLIOGRAFÍA}

Aguado de los Reyes, J. (1992): «Los Inventarios, Hamilton y el Premio de la Plata», Revista de Historia Económica, núm. 10, pp. 317-319.

Dominguez Ortiz, A. (1960): Politica y Hacienda de Felipe IV, Madrid, Editorial de Derecho Financiero.

- (1967): «La Crisis de Castilla en 1677-1687», Crisis y Decadencia en la España de los Austrias, Barcelona, Ariel.

- (1973): El Antiguo Régimen: Los Reyes Católicos y los Austrias, Madrid, Alianza Editorial.

- (1984): Política Fiscal y Cambio Social en la España del siglo XVI, Madrid, Instituto de Estudios Fiscales.

García de Paso, J. I. (1999a): «La Economía Monetaria del Padre Juan de Mariana», Moneda y Crédito, núm. 209, pp. 13.44.

- (1999b): La Politica Monetaria Castellana de Trastámaras y Austrias (1400-1700), manuscrito, Departamento de Análisis Económico, Universidad Complutense de Madrid.

Garzón Pareja, M. (1980): La Hacienda de Carlos II, Madrid, Instituto de Estudios Fiscales.

GELABERT, J. E. (1997): La Bolsa del Rey, Barcelona, Crítica.

Hamilton, E. J. (1975): El Tesoro Americano y la Revolución de los Precios en España, 1501-1650, Barcelona, Ariel.

- (1983): El Florecimiento del Capitalismo y Otros Ensayos, Madrid, Alianza Editorial.

- (1988): Guerra y Precios en España, 1651-1800, Madrid, Alianza Editorial.

KAMEN, H. (1981): La España de Carlos II, Barcelona, Crítica.

Mariana, J. de (1609) [1987]: Tratado y Discurso de la Moneda de Vellón, Madrid, Instituto de Estudios Fiscales. 
Martín ACENa, P. (1992): «Los precios en Europa durante los siglos XVI y XVII: Estudio comparativo», Revista de Historia Económica, X, 3, pp. 359-395.

Motomura, A. (1994): «The Best and Worst of Currencies: Seignoriage and Currency Policy in Spain, 1597-1650», Joumal of Economic History, 54, 1, pp. 104-127.

- (1997): «New Data on Minting, Seignoriage, and the Money Supply in Spain (Castile), 1597-1643», Explorations in Economic History, núm. 34, pp. 331-367.

Pérez Garcia, M. P. (1990): La Real Fábrica de la Moneda de Valladolid a través de sus Registros Contables, Valladolid, Universidad de Valladolid, Secretariado de Publicaciones.

Sargent, T., y Velde, F. (1999): «The Big Problem of Small Change», Journal of Money, Credit, and Banking, 31, 2, pp. 137-161.

- (1997b): «The Evolution of Small Change», Federal Reserve Bank of Chicago, working paper 97-13.

UlloA, M. (1977): La Hacienda Real de Castilla en el Reinado de Felipe II, Madrid, Fundación Universitaria Española.

Velde, F., y Weber, W. (1997): «Fiat Money in 17th Century Castile», Federal Reverve Bank of Chicago, manuscrito.

VILAR, P. (1969): Oro y Moneda en la Historia, Barcelona, Ariel. 